INTERNATIONAL JOURNAL OF SYSTEMATIC BACTERIOLOGY

Vol. 20, No. 4

October 1970

pp. $379-382$

Copyright 1970, Iowa State University Press

\title{
EXTRACTION PROCEDURES AND CELL WALL COMPOSITION, INCLUDING SOME RESULTS WITH CORYNEBACTERIA
}

\section{H. R. Perkins}

National Institute for Medical Research Mill Hill, London NW 7, England

\begin{abstract}
Cell wall preparations have been fractionated with hot formamide, lysozyme and lysozyme after pre-N-acetylation. Alsotrichloroacetic acid, cold or at $37^{\circ} \mathrm{C}$, removes polysaccharides and teichoic acids. Dimethylhydrazine, or dilute alkali, also cause specific dissolution of some cell wall components. Isolation of purified specific polymers from the cell walls of bacteria grown in controlled conditions may provide valuable taxonomic information.
\end{abstract}

The value of cell wall composition in microbial taxonomy has been stressed at this meeting. It has been apparent that, with increasing knowledge, it is the nature of the distinguishable polymers that the wall contains and their individual chemical compositions that will eventually most help taxonomists. Many extractants have been applied to cell wall preparations with the object of removing, or leaving unchanged, specific components. The mucopeptide (murein, peptidoglycan), which is the fundamental structural polymer of the cell walls, resists extraction by most chemical agents, although it is often readily dissolved by egg-white lysozyme or other specialized lytic enzymes. These enzymes have proved invaluable for resolution of mucopeptide structure, and their use has been ably reviewed ty Ghuysen (1968).

Polysaccharides, other than mucopeptide, are important constituents of the cell walls of both Gram-negative and Gram-positive bacteria. In the former group they occur principally as lipopolysaccharides and have been most commonly extracted by aqueous phenol. The composition and biosynthesis of these lipopolysaccharides have formed the subject of extensive researches, and the relationship between the serological specificity of the bacteria and the chemical composition of their lipopolysaccharides is well known (Luderitz, Staub and Westphal, 1966; Osborn, 1969). Polysaccharides are also formed in the cell walls of many Gramr positive bacteria, although it is as yet too early to see how closely their composition may be related to the taxa. One thing is clear, the presence of such polysaccharides must be sought under conditions of growth chosen for the purpose, since bacteria that do not produce a particular polysaccharide under normal conditions of batch culture may well be able to produce one, given an appropriate constraint (Tempest, 1969). Such polysaccharides have been commonly extracted either with cold trichloroacetic acid or with hot formamide. Hot formamide has been employed successfully to extract the C-polysaccharide from Group $A$ haemolytic streptococcal cell walls (Heymann, Manniello and Barkulis, 1963) and the glucose- 
acetamidomannuronic acid polymer from the cell walls of Micrococcus lysodeikticus (Perkins, 1963). Hot formamide not only removes polysaccharides but can also make the residual wall fraction (mainly mucopeptide) susceptible to the action of lysozyme (Krause and McCarty, 1961; Allsop and Work, 1963; Heymann, Manniello and Barkulis, 1964). This facility can be valuable in preliminary fractionation of bacterial cell walls before examination for taxonomic purposes, but it must be borne in mind that digestion with formamide at high temperatures can cause chemical changes other than the separation of polymers. Thus Heymann et al. (1964) found that formamide digestion at $170^{\circ}$ led to the introduction of many 0 -formyl groups that had to be removed before lysozyme could act and Perkins (1965) observed that $\omega$-amino groups, free in the cell wall preparation, also became formy lated. This blocking of free amino groups was partly responsible for the enhanced susceptibility to lysozyme. Lysozyme sensitivity could also be induced by the much milder procedure of acetylation with acetic anhydride in sodium bicarbonate solution (Perkins, 1965). The advantage of this method is that rupture of any but exceptionally labile covalent bonds is not likely to have occurred. Salton (1964) observed a similar increase of lysozyme - sensitivity after succinyla tion with succinic anhydride at $\mathrm{pH} 7.0$.

Another extractant that has been widely used is trichloroacetic acid. An aqueous solution (usually 5 or 10 percent $w / v$ ) is applied in the cold or at $37^{\circ}$, and is often effective in removing polysaccharides associated with the mucopeptide, for instance the acidic polysaccharides from Bacillus licheniformis (Janczura, Perkins and Rogers, 1961) and $\underline{M}$. Lysodeikticus (Perkins, 1963). However, the greatest use of cold trichloroacetic acid has been for the extraction of the important class of immunologically active polymers in Gram-positive bacteria, the teichoic acids (for a review, see Archibald and Baddiley, 1966). As mentioned above in connection with polysaccharides, the presence of cell-wall teichoic acids in particular strains of bacteria must always be examined after growth in suitable conditions. A shortage of phosphate in the medium can lead to a disappearance from the cell walls of a teichoic acid that may well be a characteristic product of the strain (Ellwood and Tempest, 1969).

More recently, substituted hydrazines have been advocated for the separation of teichoic acids from certain cell walls (Anderson, Archibald, Baddiley, Curtis and Davey, 1969). Some cell wall preparations , such as those of $M$. lysodeikticus, were almost completely dissolved by shaking in the presence of air $\left(60 \mathrm{~min} .80^{\circ}\right)$ with 0.2 percent NNdimethylhydrazine in 0.3 percent sodium acetate buffer, $\mathrm{pH} 5.5$. On the other hand, extraction of the cell walls of Lactobacillus arabinosus 17-5 left a residue of mucopeptide that retained the shape of original walls. Most of the cell-wall phosphate ( 86 percent) pa'ssed into solution, and the soluble products were fractionated on DEAE-cellulose. Teichoic acids and a non-teichoic acid polymer of rhamnose, glucose and glucosamine were recognized in the effluent. The authors proposed some type of free-radical mechanism for the action of the substituted hydrazines. Earlier work (Archibald and Baddiley, 1965) proposed the use of aqueous phenylhydrazine, and Grov and Rude (1967) employed this procedure to fractionate the cell walls of strains of $\underline{\mathrm{s}}$. aureus with separation of antigenic components. 
Hughes and Tanner (1968) observed that dilute alkali could be used with advantage for preferential extraction of teichoic acids from certain bacilli. For instance, whereas $0.1 \mathrm{M}$ hydrochloric acid at $35^{\circ}$. removed both teichoic and teichuronic acids from the cell walls of B. Licheniformis, O. $1 \mathrm{~N}$ sodium hydroxide, under nitrogen at the same temperature, removed 95 percent of the phosphorus (teichoic acid) in 48 hours but left the teichuronic acid intact. Other experiments showed that teichoic acid extracted in this way had not undergone appreciable alkali degradation. Archibald, Coapes and Stafford (1969) extracted other bacteria with alkali. They found that undegraded teichoic acids were extracted from Lactobacilli and Bacillus megaterium, leaving a residue of mucopeptide. Staphylococcal cell walls, however, were almost completely dissolved by alkali, so that differences in the effect of extraction with alkali obviously require careful examination.

The cell walls of plant pathogenic Corynebacteria contain large amounts of polysaccharide. Extraction with 5 percent trichloroacetic acid at $35^{\circ}$ proved the best method for separating polysaccharide and mucopeptide (no teichoic acid components could be detected, nor was anything appreciable extracted with alkali) (T. Diaz-Mauriño and H.R.

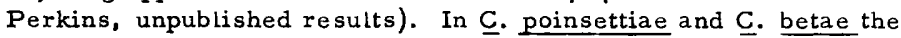
residual mucopeptide retained virtually all of the phosphorus of the cell wall, there being respectively 0.83 and 1.63 moles per mole of muramic acid. The polysaccharides from the cell walls of both species contained glucuronic acid, rhamnose and mannose and the

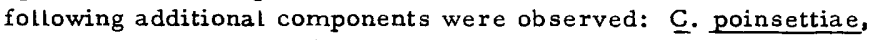
galactose, pyruvic acid: C. betae, fucose. It seems, therefore, that detailed study of cell wall polysaccharides may assist in taxonomy of this group of bacteria, as foreshadowed in the pioneering work of Cummins and Harris, (1956, 1958) and Cummins (1962).

\section{REFERENCES}

Allsop, J. and E. Work. 1963. Cell walls of Propionibacterium species: fractionation and composition. Biochem. J. 87:512-519.

Anderson, J.C., A.R. Archibald, J. Baddiley, M. J. Curtis, and N.B. Davey. 1969. The action of dilute aqueous NN-dimethylhydrazine on bacterial cell walls. Biochem. J. 113:183-189.

Archibald, A.R. and J. Baddiley. 1965. The extraction of teichoic acids from bacterial walls with phenylhydrazine and its significance for the nature of their linkage with glucosaminopeptides. Biochem. J. 95: $19 c-20 c$. and $323-375$. - 1966. The teichoic acids. Adv. Carbohyd. Chem. 2l:

, H. E. Coapes and G.H. Stafford. 1969. The action of dilute alkali on bacterial cell walls. Biochem. J. 113:899-900.

Cummins, C.S. 1962. Chemical composition and antigenic structure of cell walls of Corynebacterium mycobacterium, Nocardia, Actinomyces and Arthrobacter. J. Gen. Microbiol. 28(1):35-50.

and H. Harris. 1956. The chemical composition of the cell.wall in some Gram-positive bacteria and its possible value as a taxonomic character. J. Gen. Microbiol. 14(3):583-600. 
and - 1958. Studies on the cell-wall composition and taxonomy of Actinomycetales and related groups. J. Gen. Microbiol. $18(1): 17 \overline{3-188 \text {. }}$

Ellwood, D.C. and D. W. Tempest. 1969. Control of teichoic acid and teichuronic acid biosynthesis in chemostat culture of Bacillus subtilis var. niger. Biochem. J. 111:1-5.

Ghuysen, Jean-Marie. 1968. Use of bacteriolytic enzymes in determination of wall structure and their role in cell metabolism. Bacteriol. Rev. 32(4):425-464.

Grov, A. and S. Rude, 1967. Immunochemical examination of phenylhydrazine-treated Staphylococcus aureus cell walls. Acta path. microbiol. scand. 71:417-421.

Heymann, H., J. M. Manniello and S. S. Barkulis. 1963. Structure of streptococcal cell walls. I. Methylation study of C-polysaccharide. J. Biol. Chem, 238:502-509. and 1964 . Structure of streptococcal cell walls. III. derivative liberated by lysozyme from streptococcal glycopeptide. J. Biol. Chem. 239:2981-2985.

Hughes, R.C. and P.J. Tanner. 1968. The action of dilute alkali on some bacterial cell walls, Biochem. Biophys. Res, Commun. 33(1): 22-28.

Janczura, E., H.R. Perkins and H.J. Rogers. 1961. Teichuronic acid: A mucopolysaccharide present in wall preparations from vegetative cells of Bacillus subtilis. Biochem. J. 80:82-93.

Krause, R. $\overline{\text { M. and }} \overline{\text {. McC }}$ arty. 1961. Studies on the chemical structure of the streptococcal cell wall. I. The identification of a mucopeptide in the cell walls of groups A and A-variant streptococci. J. Exp. Med. 114(1):127-140.

Lüderitz, O., A. M. Staub and O. Westphal. 1966. Immunochemistry of $O$ and $R$ antigens of Salmonella and related Enterobacteriaceae. Bact. Rev. 30(1):192-255.

Osborn, $\bar{M}$. J. 1969. Structure and biosynthesis of the bacterial cell wall. Ann. Rev. Biochem. 38:501-538.

Perkins, H. R. 1963. A polymer containing glucose and aminohexuronic acid isolated from the cell walls of Micrococcus lysodeikticus. Biochem. J. 86:475-483.

- 1965. The action of hot formamide on bacterial cell walls. Biochem. J. 95:876-882.

Salton, M.R.J. $\overline{19} 64$. Méd. et Hyg. 22:985.

Tempest, D.W. 1969. Quantitative relationship between inorganic cations and anionic polymers in growing bacteria. In: Microbiol Growth.

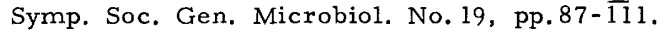

